\title{
Conflicting visual and tactual-kinesthetic stimulation ${ }^{1}$
}

JO ANN S. KINNEY ${ }^{2}$ AND S. M. LURIA NA VAL SUBMARINE MEDICAL CENTER

The relative importance placed on visual rather than tactual or kinesthetic cues was investigated under water. In matching disks of various sizes to common coins from memory, Ss consistently chose disks much smaller than the actual size of the coins and more closely approximating their optical size in the water, even when permitted to see their own hands. In a second experiment, the performance of a motor task, learned to criterion while blindfolded, was significantly more disrupted under water than in air when $S$ s were permitted to look. Both sets of results demonstrate the dominance of vision over the other two senses. The importance of the underwater environment as a naturally distorted one, requiring no lenses or prisms to produce optical distortions, is emphasized.

A number of investigators have addressed their attention in recent years to a question of perceptual conflict, the result of presenting conflicting information to two different senses. Several studies have shown that when vision and touch signal different data, vision predominates; that is, a unified impression results which rests almost entirely on the visual information (Howard \& Templeton, 1966, pp. 359-362; Epstein, 1967, p. 246). The conflicting tactual-kinesthetic information is disregarded; indeed, $S$ may even be unaware of the discrepancy. Howard and Templeton (1966) have called this general phenomenon "stimulus dominance," and Hay, Pick, and Ikeda (1965) have coined the more arresting term, "visual capture."

Harris (1965) and Rock and Harris (1967) have argued persuasively that these results refute the classical theory of perception in which the development of visual organization is based on tactual experience. The question of the generality of the results is thus of obvious importance because of their relevance to perceptual theory.

The study of conflicting sensory information in the psychological laboratory requires lenses, prisms, pseudophones, or other encumbrances which make it difficult to assure the naivete of $S$. There is at least one natural environment, however, that presents conflicting stimulation to the visual and tactual senses: the underwater environment. Here tactual sensations of size are the same as they are in the air, but visual stimuli are distorted by the refraction of the light rays as they pass from water to air in the diver's face mask. A virtual image is created at three-fourths of the distance from the interface to the object. The retinal image created from this virtual image is thus larger than the image from the same object in air by a factor of about 1.3-the exact amount of magnification depends on the distance of the eye from the interface. With a typical face mask, the magnification is approximately $27 \%$. Also, the apparent location of the object in water is displaced from its true location.

This study investigated the relative importance placed on vision compared to that placed on touch or kinesthesis in the underwater situation.

\section{EXPERIMENT 1}

The first experiment investigated the response of naive $S s$ to this optical distortion and also the relative importance placed on vision and touch in judging the size of familiar objects under water.

\section{Method}

Memory for the size of coins was selected as the task, because it seemed reasonable to assume that most individuals are highly practiced in picking out coins on both a visual and a tactual basis. Four common coins, a dime, penny, nickel, and quarter, were chosen as the memory standards. A series of 16 aluminum disks were provided whose diameters varied from .5 to 1.3 in., well encompassing the range of diameters of the four coins. The S's task was to select from memory the disk most representative in diameter of a dime, penny, nickel, or quarter.

Each $S$ repeated the task in the water

Table 1

Size of Disks Selected to be Representative of Various Coins. Means and Standard Deviations in Inches

\begin{tabular}{lccccc}
\hline & \multicolumn{2}{c}{ Air } & & \multicolumn{2}{c}{ Water } \\
\cline { 2 - 3 } \cline { 5 - 6 } Coin & $\begin{array}{c}\text { Vision } \\
+ \text { Touch }\end{array}$ & Touch & & Vision & $\begin{array}{c}\text { Vision } \\
\text { + Touch }\end{array}$ \\
\hline $\begin{array}{l}\text { Dime } \\
(.70 \text { in. })\end{array}$ & $.69 \pm .05$ & $.72 \pm .04$ & $.55 \pm .04$ & $.56 \pm .05$ \\
$\begin{array}{l}\text { Penny } \\
(.75 \text { in. })\end{array}$ & $.77 \pm .04$ & $.77 \pm .04$ & $.61 \pm .03$ & $.63 \pm .04$ \\
$\begin{array}{l}\text { Nickel } \\
(.84 \text { in. })\end{array}$ & $.84 \pm .05$ & $.85 \pm .04$ & $.68 \pm .06$ & $.71 \pm .05$ \\
$\begin{array}{l}\text { Quarter } \\
(.95 \text { in. })\end{array}$ & $.98 \pm .04$ & $.99 \pm .05$ & $.80 \pm .09$ & $.83 \pm .06$ \\
\hline
\end{tabular}

under two sets of instructions. He was asked to pick up and hand each coin to E, when called for, and he was also asked to select each coin by giving its number without actually touching it. The disks were numbered on one side only, so that they could be turned upside down and identified by number, or not, as dictated by which of the instructions was being used. Half of the Ss made their first selection visually; the other half started with the visual-tactual condition.

Several control conditions were also included. The same Ss performed the task in air, under the instruction to pick up and hand each coin to E. The Ss also performed the task in air while blindfolded, to be sure that it was possible on a tactual basis. In addition, six of the Ss performed the task blindfolded in the water to assure that immersion would not, by itself, systematically bias the results. The first task was performed in air by half of the Ss and in water by the other half. The Ss were assigned to these groups at random.

The experiment was conducted outside in natural daylight. The coins were arranged on a table top for viewing by the $\mathrm{S}$. For the water condition, the table was immersed in an above-ground swimming pool. The Ss were fitted with a face mask and a snorkel.

\section{Subjects}

Twenty Ss were randomly selected from the population available at the laboratory during the summer. These included students, sailors, and laboratory personnel. The only basis for rejection was scuba experience or lack of a bathing suit.

\section{Results}

The average results for the 20 Ss are presented in Table 1. The sizes, means, and 


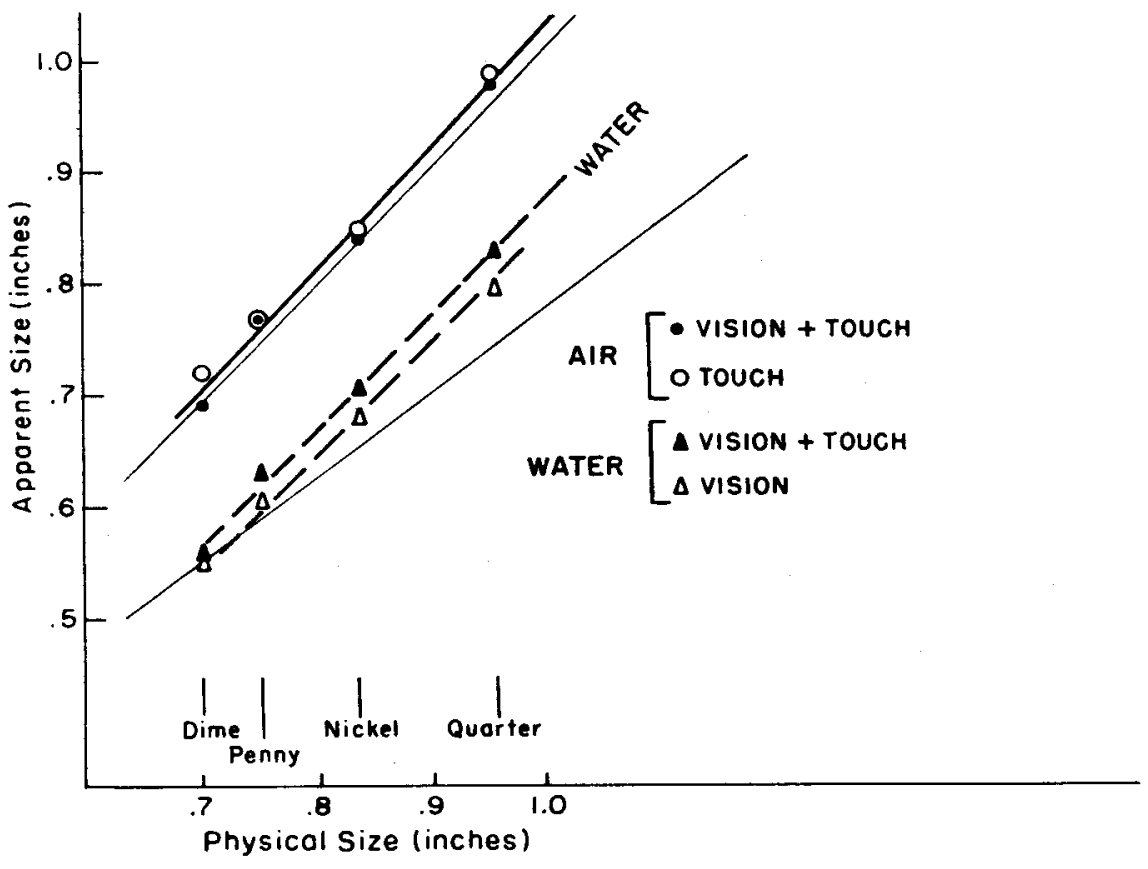

standard deviations of the comparison disks chosen as equal in size to the dime, penny, nickel, and quarter are given for each condition. These data are plotted in Fig. 1 as a function of the actual physical size of the coins. The theoretical correspondence with either physical or optical size is indicated by the thin solid lines.

The control data, obtained in air, revealed that the task of selecting disks of appropriate size for different coins was an easy one for most Ss. The size estimates agreed well with the actual physical size of the coins. Furthermore, the Ss were just as accurate by touch alone as they were when making visual comparisons. Standard deviations, computed separately for the visual and tactual data, were very small, varying from .04 to .05 , and almost exactly the same. Thus greater variability was not displayed for either sense. There was no difference between the tactual data obtained in water and in air.

In water, all Ss consistently chose disks that were much smaller than the actual size of the coins; there was, however, good correspondence between the responses and the optical image size. For example, a disk of .55-in. diam, when multiplied by the magnification factor of 1.27 , assumes a size

Fig. 2. Mean size of disks chosen as equal in size to various coins by Ss whose underwater experience was only visual (left) and by Ss whose first underwater experience was both visual and tactual (right). The vertical lines show the standard deviations about the means.
Fig. 1. Mean size of disks chosen as equal in size to various coins under the different experimental conditions. The thin diagonal lines represent the values corresponding to actual physical size (top) and to the size calculated from optical refraction (bottom).

for all 20 Ss who performed the same task in each experimental situation. It is also possible to analyze only half of the data, dividing the Ss into two groups according to whether their first task in the water was visual or visual and tactual. This analysis is shown in Fig. 2.

For those $10 \mathrm{Ss}$ whose first experience in water was to select the coins by vision alone, the agreement between the calculated sizes of the optical image and the actual estimates was almost perfect. The estimates made by the $10 \mathrm{Ss}$ who actually picked up the coins were larger than the estimates made on a purely visual basis. The difference, however, cannot be attributed to the tactual sense alone, for the Ss were in a completely free environment and, thus, were allowed to see their own hands. Occasionally a $S$ was seen reaching for a disk, and, after his hand came into view, changing and reaching for a larger disk. Even with this additional information available, however, these Ss selected a disk only one step size larger. If they had been consciously comparing disk size to the size of their hands, the choice should have been four to five steps larger.

\section{EXPERIMENT 2}

It might be argued that in everyday life the selection of coins is predominantly a visual affair when both types of information are available, and that most individuals have a well-learned response bias in favor of vision.

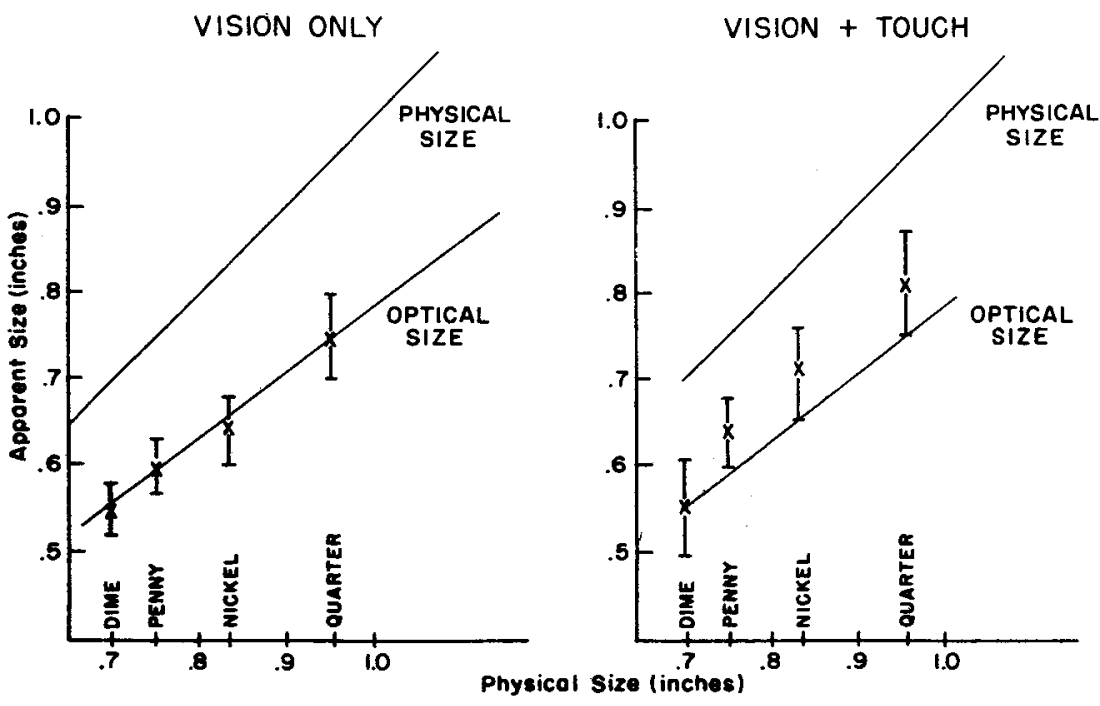




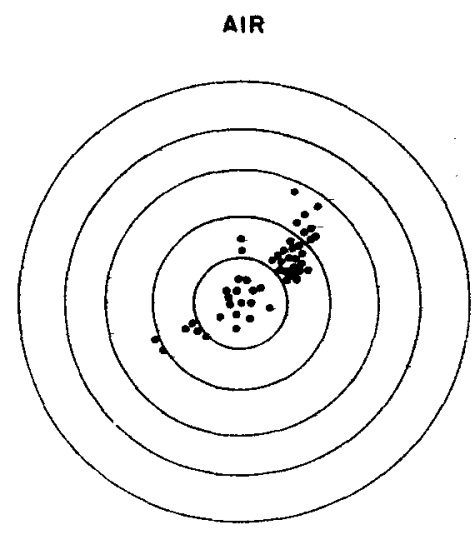

A second experiment was therefore designed to give Ss tactual-kinesthetic experience while excluding all visual experience. A reasonably difficult motor task was learned to criterion while blindfolded, after which visual cues were pitted against the kinesthetic cues. The experiment tested the degree to which performance was subsequently disnupted by the visual cues-distorted or not-which had to that time played no part in carrying out the task.

\section{Method}

The experimental task was to hit the bullseye of a target with a $1-\mathrm{ft}$ stick while blindfolded. The target was an $18 \times 20$ in. metal sheet with a 2-in.-diam circle cut out in the center. The $\mathrm{S}$ knelt with the target at a 45-deg angle to his midfrontal plane (making a longer distance on the right side) and held the upper left corner at arm's length. Between thrusts, he was required to bring his arm down completely by his side. The Ss were given daily practice sessions until they had attained the criterion: they were required to hit the bullseye 9 times out of 10 attempts on 3 consecutive days with no more than six warm-up thrusts. ${ }^{3}$

Immediately after successfully completing the third day's run, $S$ was tested. A plate was bolted across the hole so that he would no longer know when he had hit the bullseye. The blindfold was removed, and $S$ was permitted to look at the target. He was then told to close his eyes, and a screen was lowered in front of his head. He made a thrust, and his score was recorded. The screen was raised, and he was permitted another look at the target. He closed his eyes, the screen was lowered, and he made another thrust, and so on for 10 trials. Before the test began, $S$ was reminded that he had now learned to hit the target blindfolded, and it would be well to continue to rely on the kinesthetic cues even though he was now permitted to look between thrusts.

The Ss were divided randomly into two

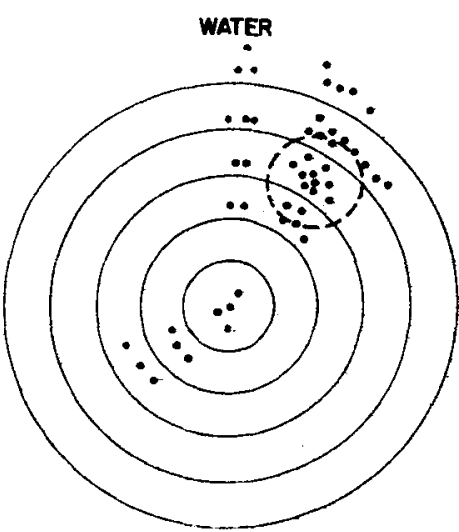

groups. One group learned the task first in water and later in air; the second group learned it first in air. The only difference between the two conditions was that in the water condition the Ss, of course, wore snorkels while kneeling in water $4 \mathrm{ft}$ deep. A face mask was worn in air as well as in the water.

\section{Subjects}

Five staff members of the laboratory served as Ss. None was highly experienced in diving or snorkeling; all were right-handed. Three were in the water-first condition and two were in the air-first condition. It was originally planned to have four Ss in each group, but one S left the laboratory in the middle of the experiment and two Ss declined to complete the water condition.

\section{Results}

The scores made by the five $S s$ in the two conditions are shown in Fig. 3. This depicts the target with its 2 -in. bullseye and concentric rings of $l$ in. in width. Hitting the center gave a score of 1 ; each successive ring added 1 point to the score. Missing the rings completely resulted in a score of 6 , regardless of how far away the hit was. Our calculations of the optical image made from the position of S's head and angle of the face mask indicate that the thrusts should have been made in the 1:00 to 2:00 o'clock position about 3 in. from the bullseye if $S$ were relying on the visual stimulus. Figure 3 shows that in air there were 15 hits in the center and no hit farther away from the center than the second ring. The mean score was 1.90 for the 50 trials. In the water, the mean score was 4.02 , and there were eight hits outside the limits of the target. It is worth noting that the four hits in the center and the six hits around 8:00 o'clock for the water condition were all by the same $S$, who-it was clear from other underwater experiments-was aware of the optical distortions in the water and was making a
Fig. 3. Test results showing the location of the 10 thrusts made by each of the five Ss in air and in the water. The broken circle indicates the apparent location of the bullseye, calculated from the position of So' heads and the angle of the face masks.

conscious effort to compensate for them. The $t$ test for correlated means of the difference between these two sets of data shows them to be significantly different $(t=10.01, \mathrm{df}=6, \mathrm{p}<.001)$.

It is clear from both these experiments that visual cues, when made available, have a commanding effect on $S$ 's performanee. When these cues are distorted, performance is degraded to a considerable extent, even when the task involves well learned kinesthetic cues that have just proved adequate to permit carrying out that task.

\section{DISCUSSION}

Two points should be emphasized in connection with these data. First, the present results have demonstrated once again the dominance of vision over touch and kinesthesis, this time in a situation in which the conflicting stimulation to the different senses arises in a completely natural environment devoid of any intrusive artificial manipulations by $\mathrm{E}$. This reliance on visual information is so compelling that Ss will ignore, by and large, extraneous visual stimulation on the nature and magnitude of the distortion-stimulation they could use to consciously correct their erroneous responses. Furthermore, most Ss apparently cannot inhibit responses based on visual stimuli even though the visual information is unnecessary to successful response.

Second, the underwater world provides an ideal environment for investigations of human adaptation to distorted stimulation in the sense that $E$ need not produce these visual distortions himself; $S$ is never required to wear unexpected and irrelevant equipment simply for experimental purposes; many Ss are thus completely unaware that visual distortions exist. Yet, our investigations in this area show that hand-eye coordinations and perceptual-motor behavior show adaptation comparable to that found in air when distorting prisms are used (Kinney et al, 1968).

Of considerable theoretical interest is the question of whether all adaptation involves changes in the sense of the limbs, the head, or the eyes. For the underwater environment, the question becomes "does extensive underwater experience eventually result in congruence between perceived size and physical size or do objects under water always appear too large even though one 
can manipulate them appropriately?" Measures of size perception, such as this one, conducted on highly experienced divers may answer this question; we are currently conducting such studies.

\section{REFERENCES}

EPSTEIN, W. Varieties of perceptual learning. New York: McGraw-Hill, 1967. Pp. 187-418.

HARRIS, C. S. Perceptual adaptation to inverted, reversed, and displaced vision. Psychological Review, 1965, 72, 419-444.

HAY, J. C., PICK, H. L., \& IKEDA, K. Visual capture produced by prism spectacles. Psychonomic Science, 1965, 2, 215-216.

HOWARD, I. P., \& TEMPLETON, W. B. Human spatial orientation. New York: Wiley, 1966, 367-418.

KINNEY, J. A. S., LURIA, S. M., \& WEITZMAN, D. O. Responses to underwater distortions of visual stimuli. Naval Submarine Medical Center, Groton, Conn., Report No. 541 , July 1968 .

ROCK, I., \& HARRIS, C. S. Vision and touch. Scientific American, 1967, 216, 96-107.

\section{NOTES}

1. From Bureau of Medicine and Surgery, Navy Department, Research Work Unit MF12.425.004-9014D. The opinions or assertions contained herein are the private ones of the authors and are not to be construed as official or reflecting the views of the Navy Department or the Naval Service at large.

2. Address: Vision Branch, Naval Submarine Medical Center, Box 600, Groton, Connecticut 06340.

3. The $S$ determined the length of his practice session. It lasted until he got tired or cold or until he felt that no further progress would be made that day. Most Ss 1zached criterion within 10 days, but one $S$ in each experimental group required about 30 days for the first condition. The second condition was generally learned more quickly than the first.

(Accepted for publication November 14, 1969.) 